\title{
Deposition rule of yolk cholesterol in two different breeds of laying hens
}

\author{
P.K. Yang*, Y.D. Tian*, G.R. Sun, R.R. Jiang, R.L. Han and X.T. Kang \\ College of Livestock Husbandry and Veterinary Engineering, \\ Henan Agricultural University, Zhengzhou, China \\ *These authors contributed equally to this study. \\ Corresponding author: X.T. Kang \\ E-mail: xtkang2001@263.net
}

Genet. Mol. Res. 12 (4): 5786-5792 (2013)

Received February 26, 2013

Accepted July 29, 2013

Published November 22, 2013

DOI http://dx.doi.org/10.4238/2013.November.22.5

\begin{abstract}
The objective of this study was to investigate the deposition rule of yolk cholesterol in Lushi Green-shelled and Silky Fowl layers. A total of 90 layers of each breed were selected at an age of 15 to 51 weeks. Productive performance was recorded on a weekly basis, whereas yolk cholesterol was determined at 4 -week intervals from 21 to 51 weeks of age. The average yolk cholesterol content of Silky Fowl layers during the laying period was higher than that of Lushi Green-shelled layers (58.16 and 49.67\%, P $>0.05)$. Yolk cholesterol content decreased at 21 to 31 weeks of the laying period, whereas a non-significant increasing trend was observed during 31 to 51 weeks of laying period. In conclusion, yolk cholesterol content is not only dependent on the age of hen but also the breed of layers.
\end{abstract}

Key words: Chicken; Cholesterol content; Egg yolks; Breed; Age; Layer 


\section{INTRODUCTION}

Cholesterol is a major structural component of cell membranes, a precursor for many steroid hormones and bile acids (Myant, 1990). Excessive cholesterol levels in the body lead to the risk for the development of atherosclerosis, so precise control of plasma cholesterol levels is of key importance (Khera et al., 2011). The importance of high serum cholesterol levels as a risk factor for coronary heart disease and the benefit of lowering cholesterol levels for reducing risk are increasingly accepted worldwide (Grundy, 1986). The evidence correlating serum cholesterol levels with coronary heart disease was established from early observations (Hargis, 1988; de Goede et al., 2012).

An experimental study by Baumgartner et al. (2008) concluded that chicken eggs supply about $30 \%$ of dietary cholesterol in the American diet The public's perception of the role of eggs in the diet has changed over the past 50 years. Eggs are considered to be an important contributor to high serum cholesterol levels and an increased risk of cardiovascular disease (Simcic et al., 2009). Therefore, egg consumption per capital has been declining in many countries because of concerns associated with cholesterol (Suk and Park, 2001).

It is well established that eggs are nutritionally rich, highly digestible food. Concerning the cholesterol problem caused by the influence of negative publicity of egg cholesterol, research efforts directed towards reducing yolk cholesterol content are now mainly focused on the genetic selection or modification of the laying hens' diet with various nutrients, natural products, non-nutritional factors, or pharmacological agents (Elkin, 2006). Some research has indicated that the cholesterol content of eggs is influenced by genetic factors (Shafey et al., 1998), dietary composition (McNaughton, 1978; Liu et al., 2010), laying intensity (Mahmoud et al., 2010), layer age (Hall and Mckay, 1993), and medical treatment (Simcic et al., 2009). Great progress has been made in this field, but the trend of yolk cholesterol content with layer age is not very well known.

The objective of the present study was to investigate the effects of genetic breeds and the age of hens on yolk cholesterol content and to explore the rule of cholesterol content in egg yolks.

\section{MATERIAL AND METHODS}

\section{Bird management}

Ninety birds, 15 weeks old for each breed, were housed in a wire-floored cage measuring $45 \times 40 \mathrm{~cm}$ with a height of $45 \mathrm{~cm}$. Three hens were placed per cage, consisting of 5 cages per replicate. There were 6 replicates per treatment. All hens were allowed free access to their respective feed and water. The photoperiod was set at a 16-h light/ 8 -h dark cycle throughout the 30-week experiment. Room temperature was maintained at $25^{\circ} \pm 5^{\circ} \mathrm{C}$. Eggs from both breeds were collected and counted daily.

\section{Determination of cholesterol}

During 21 to 51 weeks of the laying period, three eggs were randomly selected at 5 -week intervals from each replicate, and were weighed and broken. Yolk and albumen were 
separated to measure the cholesterol content of the egg. Prior to weighing the yolk, the chalazae were carefully removed using forceps.

The yolk sample $(5.000 \mathrm{~g}$ ) was diluted with $0.9 \% \mathrm{NaCl}$ to $50 \mathrm{~mL}$, and $5 \mathrm{~mL}$ diluted egg yolk was mixed with $5 \mathrm{~mL} 50 \% \mathrm{KOH}$ and $3 \mathrm{~mL} 95 \%$ ethanol. The mixture was then heated in a water bath at $60^{\circ} \mathrm{C}$ for $1 \mathrm{~h}$ and allowed to cool under running water before adding $5 \mathrm{~mL}$ distilled water. Cholesterol was extracted twice with $10 \mathrm{~mL}$ hexane. An aliquot $(0.5$ $\mathrm{mL}$ ) of the hexane extract was dried in a vacuum drying oven, dissolved in $0.5 \mathrm{~mL}$ methanol and separated by HPLC.

Agilent 1100 was used as the HPLC apparatus in this experiment. The analytical column was Hypersil BDS C18 $(0.46 \mathrm{~cm} \times 15 \mathrm{~cm}, 5 \mu \mathrm{m})$, preceded with an Agilent C18 $(0.46 \mathrm{~cm} \times 10 \mathrm{~mm}, 5 \mu \mathrm{m})$ guard column. The mobile phase (flow rate, $1 \mathrm{~mL} / \mathrm{min}$ ) consisted of methanol. Each run took $20 \mathrm{~min}$. Absorption spectra were taken at 190-300 nm and the chromatograms were at $205 \mathrm{~nm}$.

Additionally, a certified reference material, pure cholesterol reference material (GBW09203a, China), was obtained from China Standard Material Net.

All solvents were reagent grade for extraction and HPLC grade for chromatography. Quantification was carried out by external standardization. The standard curves were linear and bracketed the sample concentrations. Calibration was done on each day of analysis.

\section{Statistical analysis}

Data were analyzed on the basis of breed and age of hen by using GLM (SPSS11.0). $\mathrm{P}<0.05$ was considered to be significant.

\section{RESULTS}

\section{Laying performance}

Weekly laying performances of Lushi Green-shelled layers and Silky Fowl layers during 21 to 51 weeks are shown in Figure 1. At 21 to 24 weeks of age, laying efficiency of the two selected breeds increased quickly and reached a peak at 24 weeks of age, with a laying rate of 66.38 and $53.75 \%$ for Lushi Green-shell and Silky Fowl layers, respectively. These breeds maintained peak laying performance for approximately 18 weeks, and afterwards, laying efficiency decreased gradually to $48.45 \%$ (Lushi Green-shelled layers) and $44.79 \%$ (Silky Fowl layers) at the age of 50 weeks. During the entire laying period (21 to 51 weeks of age), productivity of Lushi Green-shelled layers was higher than that of Silky Fowl layers. Average laying performance of Lushi Green-shelled layers (58.16\%) was not significantly higher than that of Silky Fowl layers (49.67\%) from 21 to 51 weeks $(\mathrm{P}>0.05)$.

\section{Yolk cholesterol content}

Egg yolk cholesterol levels influenced by the two breeds at different ages are presented in Table 1. The effect of breed, age of hens and breed-by-age-of-hen interactions on the cholesterol content in yolk varied significantly. 


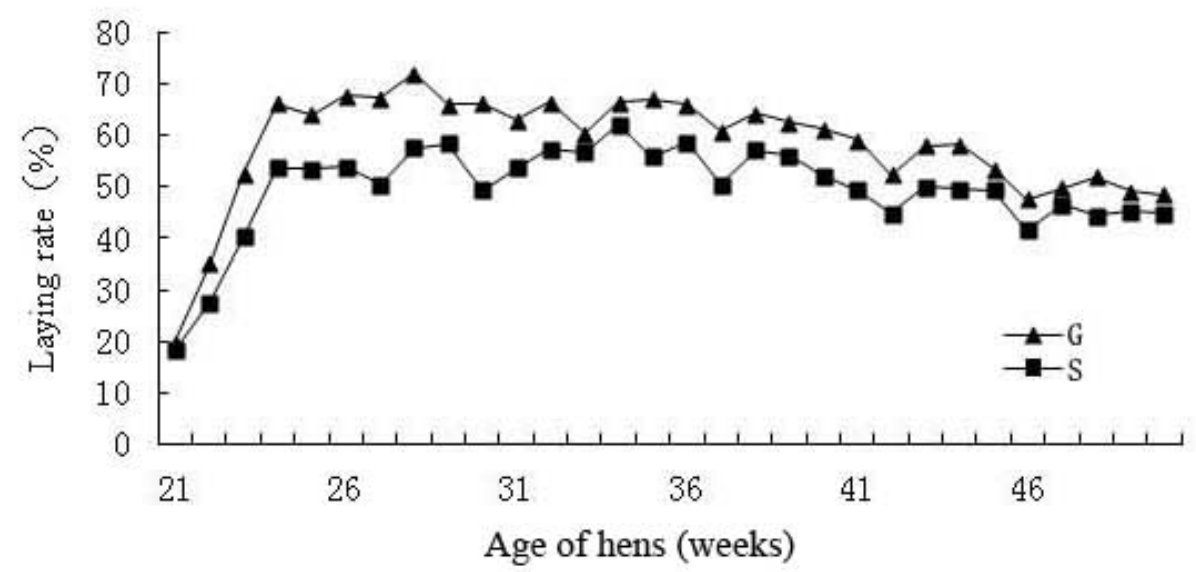

Figure 1. Laying rate of two different layers at 21 to 51 weeks. Triangles (G) stand for laying rate of Lushi Greenshelled layer; squares (S) stand for laying rate of Silky Fowl layer.

Table 1. Effects of breed and age within a breed on cholesterol content in yolk.

\begin{tabular}{lcrcccc}
\hline Breed & Age (weeks) & S N & Egg weight $(\mathrm{g})$ & Yolk weight $(\mathrm{g})$ & Yolk ratio & Cholesterol content $(\mathrm{mg} / \mathrm{g}$ yolk $)$ \\
\hline $\mathrm{G}$ & 21 & 20 & $33.2698 \pm 2.1276^{\mathrm{f}}$ & $9.2303 \pm 0.6880^{\mathrm{e}}$ & $27.7827 \pm 1.8601^{\mathrm{c}}$ & $8.8201 \pm 1.5081^{\mathrm{a}}$ \\
& 26 & 20 & $38.5353 \pm 1.9684^{\mathrm{c}}$ & $11.2549 \pm 0.6997^{\mathrm{d}}$ & $29.2148 \pm 1.2696^{\mathrm{b}}$ & $7.6325 \pm 0.5631^{\mathrm{b}}$ \\
& 31 & 20 & $42.6081 \pm 1.7946^{\mathrm{d}}$ & $12.8299 \pm 0.4998^{\mathrm{c}}$ & $30.1542 \pm 1.5873^{\mathrm{b}}$ & $6.3457 \pm 1.6715^{\mathrm{c}}$ \\
& 36 & 20 & $44.1827 \pm 1.5187^{\mathrm{c}}$ & $14.3764 \pm 0.5411^{\mathrm{b}}$ & $32.5650 \pm 1.4442^{\mathrm{a}}$ & $8.2071 \pm 1.0646^{\mathrm{ab}}$ \\
& 41 & 20 & $46.0434 \pm 2.0014^{\mathrm{b}}$ & $14.8623 \pm 1.0485^{\mathrm{b}}$ & $32.2798 \pm 1.7987^{\mathrm{a}}$ & $8.8954 \pm 1.5001^{\mathrm{a}}$ \\
Overall & 46 & 20 & $47.9960 \pm 2.1824^{\mathrm{a}}$ & $15.6484 \pm 1.2533^{\mathrm{a}}$ & $32.5832 \pm 1.7681^{\mathrm{a}}$ & $7.8130 \pm 1.3619^{\mathrm{ab}}$ \\
$\mathrm{S}$ & 51 & 20 & $48.8592 \pm 2.0099^{\mathrm{a}}$ & $15.9577 \pm 0.7415^{\mathrm{a}}$ & $32.6827 \pm 1.4325^{\mathrm{a}}$ & $8.2249 \pm 0.9439^{\mathrm{ab}}$ \\
& 21 & 20 & $32.7593 \pm 1.3596^{\mathrm{e}}$ & $8.7364 \pm 0.4317^{\mathrm{e}}$ & $26.7044 \pm 1.5839^{\mathrm{d}}$ & $11.1269 \pm 1.3922^{\mathrm{a}}$ \\
& 26 & 20 & $37.4367 \pm 2.1127^{\mathrm{d}}$ & $10.7983 \pm 0.7359^{\mathrm{d}}$ & $28.8890 \pm 1.9827^{\mathrm{c}}$ & $9.2138 \pm 0.7274^{\mathrm{bc}}$ \\
& 31 & 20 & $40.3132 \pm 1.9119^{\mathrm{c}}$ & $11.8846 \pm 0.9787^{\mathrm{c}}$ & $29.5069 \pm 2.3646^{\mathrm{bc}}$ & $8.9311 \pm 0.8403^{\mathrm{c}}$ \\
& 36 & 20 & $42.5872 \pm 1.6299^{\mathrm{b}}$ & $13.0166 \pm 0.6292^{\mathrm{b}}$ & $30.6092 \pm 1.9361^{\mathrm{ab}}$ & $9.4153 \pm 1.0119^{\mathrm{bc}}$ \\
& 41 & 20 & $44.6057 \pm 2.2886^{\mathrm{a}}$ & $13.7196 \pm 1.1298^{\mathrm{a}}$ & $30.8147 \pm 2.7309^{\mathrm{ab}}$ & $9.7403 \pm 1.2967^{\mathrm{bc}}$ \\
& 46 & 20 & $44.8536 \pm 1.9807^{\mathrm{a}}$ & $14.3731 \pm 0.9413^{\mathrm{a}}$ & $32.0738 \pm 2.0916^{\mathrm{a}}$ & $9.6981 \pm 1.2559^{\mathrm{bc}}$ \\
& 51 & 20 & $44.4870 \pm 1.9871^{\mathrm{a}}$ & $14.1039 \pm 1.2647^{\mathrm{a}}$ & $31.6966 \pm 2.3999^{\mathrm{a}}$ & $10.1004 \pm 1.0558^{\mathrm{b}}$ \\
& & 140 & $41.0654 \pm 4.5768^{\mathrm{y}}$ & $12.4023 \pm 2.0866^{\mathrm{y}}$ & $30.0661 \pm 2.7335^{\mathrm{y}}$ & $9.7366 \pm 1.2650^{\mathrm{x}}$ \\
\hline
\end{tabular}

${ }^{\mathrm{a}-\mathrm{f}} \mathrm{M}$ eans within each column with a breed without common superscripts are significantly different at $\mathrm{P}<0.05$.

${ }^{x y}$ Overall means between breeds in each column without common superscripts are significantly different at $\mathrm{P}<0.05$. $\mathrm{G}=$ Lushi Green-shelled layer; $\mathrm{S}=$ Silky Fowl layer.

Regarding the overall means during the laying period, egg yolk cholesterol of Silky Fowl layers $(9.74 \mathrm{mg} / \mathrm{g}$ yolk) was significantly higher than that of Lushi Green-shelled layers $(7.99 \mathrm{mg} / \mathrm{g}$ yolk) $(\mathrm{P}<0.05)$. The same results of higher egg yolk cholesterol content for Silky Fowl were obtained for each week of observation, during the study period.

Significantly lower egg yolk cholesterol was observed in the eggs of Lushi Greenshelled layers at the age of 31 weeks $(6.35 \mathrm{mg} / \mathrm{g}$ yolk), as compared with Silky Fowl layers (P $<0.05)$. Egg yolk cholesterol at 21 weeks $(8.82 \mathrm{mg} / \mathrm{g}$ yolk) and 41 weeks $(8.90 \mathrm{mg} / \mathrm{g}$ yolk) was higher than that of the 26-31-week period $(\mathrm{P}<0.05)$, whereas egg yolk cholesterol content of eggs of the 36-51-week period was not significantly different $(\mathrm{P}<0.05)$.

The eggs from Silky fowl layers contained the lowest egg yolk cholesterol content at 31 weeks of age $(8.93 \mathrm{mg} / \mathrm{g}$ yolk$)$, as compared with that of $21-51$ weeks of age $(\mathrm{P}<0.05)$; the 
cholesterol content in yolk at 21 week $(11.13 \mathrm{mg} / \mathrm{g}$ yolk) was higher than that at other ages (P $<0.05)$, whereas the egg yolk cholesterol at 26-46 weeks of the laying period was not significantly different $(\mathrm{P}<0.05)$.

The trend line of egg yolk cholesterol content fluctuating with age of hens is shown in Figure 2. Cholesterol content in yolk decreased in the 21-31-week period and increased in the 31-51-week period between the two different genetic breeds. The yolk cholesterol content at 21 weeks of age was the lowest and that at 31 weeks was the highest in the period from 21 to 51 weeks of age between the two different genetic breeds.

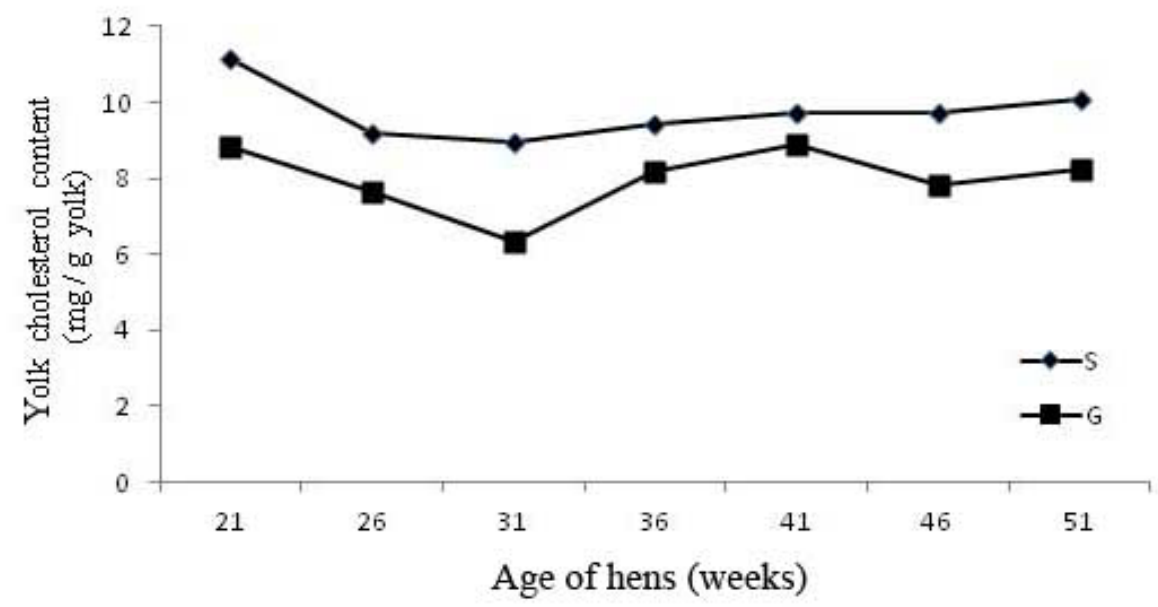

Figure 2. Yolk cholesterol content in two different layers. Lozenges (S) stands for cholesterol deposition of Silky Fowl layer; squares $(\mathrm{G})$ stand for cholesterol deposition of Lushi Green-shelled layer.

\section{Deposition of yolk cholesterol}

The factors that could have an effect on egg yolk cholesterol, namely age of hens (A), laying rate (LR), egg weight (EW), and yolk weight (YW), were taken as the independent variables for the regression equation. Equation 1 was used to estimate the egg yolk cholesterol content of Lushi Green-shelled layers, whereas Equation 2 was used for the estimation of Silky Fowl egg yolk cholesterol.

$$
\begin{array}{ll}
\mathrm{y}=27.878+0.176 \mathrm{~A}+0.007 \mathrm{LR}-1.253 \mathrm{EW}+2.034 \mathrm{YW}(\mathrm{R}=0.889) & (\text { Equation } 1) \\
\mathrm{y}=9.853+0.057 \mathrm{~A}-0.045 \mathrm{LR}+0.238 \mathrm{EW}-0.796 \mathrm{YW}(\mathrm{R}=0.943) & (\text { Equation } 2)
\end{array}
$$

\section{DISCUSSION}

Cholesterol content of egg yolk can be influenced by breed, strain and age of the hen. In addition, an inverse relationship exists between egg yolk cholesterol content and both the rate of egg production and the yolk size (Elkin, 2006). Genetic variations in egg yolk cholesterol have been found to be associated with egg production, egg weight, and yolk size (Shafey et al., 1998). 
Due to the different lipid metabolism and physiological metabolic characteristics of different species or strains, egg yolk cholesterol concentration or content levels of different varieties in the same period are significantly different (Campo, 1995). In the present study, the yolk cholesterol content of Silky Fowl layers tended to be greater than that of Lushi Greenshelled layers, which is in agreement with the results of Campo (1995). He reported that egg yolk cholesterol concentrations vary depending on the genetic strain of the laying hens. However, this is contrary to the study of Bragagnolo and Rodriguez-Amaya (2003), who found that there was no significant difference in the cholesterol content of large, white- or dark-shelled eggs in terms of $\mathrm{mg} / \mathrm{g}$ yolk. These results may be due to difference in ages of the hens.

Lushi Green-shelled layers as compared with the Silky Fowl layer showed greater egg yolk cholesterol content, whereas the laying rate of the Lushi Green-shelled layers was significantly higher than that of Silk Fowl layers. This finding is consistent with that of Vargas and Naber (1984), who reported that a significant negative correlation was found between yolk cholesterol and egg production.

Differences in yolk cholesterol content between different periods in the present study were highly significant. Egg yolk cholesterol content decreased with age of the hens from 21 to 31 weeks of age, which is in agreement with the results of previous studies that also found that egg yolk cholesterol decreases with the age of hens in experiments using different strains of birds (Jiang and Sim, 1991; Hall and Mckay, 1993).

The findings that egg yolk cholesterol tended to increase with the age of hens as they progressed from 31 weeks old to 51 weeks old are in line with the results reported by Menge et al. (1974) and Shafey et al. (1998). The first authors found that yolk cholesterol concentration increased with age of the hens. The latter group reported that egg cholesterol content at 30 weeks of age was approximately 19\% lower than that determined at 56 weeks of age. Thus, there was a significant positive correlation between age of the hens and yolk cholesterol concentration. Jiang and Sim (1991) reported that yolk cholesterol concentration in mg/g yolk decreased during the first 6 months of egg production.

However, Palafox (1968) stated that yolk cholesterol content of eggs was not significantly affected by age of birds. Spencer et al. (1978) also reported that cholesterol concentration did not change with the age of birds, i.e. eggs laid by 12.5 -month-old hens and the same hens at 11 months old. In the present study, the yolk cholesterol content of eggs was not significantly different in 31- to 51-week-old hens.

During the laying period from 21 to 51 weeks, yolk cholesterol content decreased in the period of 21 to 31 weeks and tended to increase in the period of 31 to 51 weeks, but the differences were not significant. The finding was consistent with the results of Hall and Mckay (1993), who observed that yolk cholesterol concentration decreased between 20 and 30 weeks of age, and then remained constant until 70 weeks of age.

We conclude that the strain and age of laying hens can significantly influence egg yolk cholesterol content. The egg yolk cholesterol content of Silky Fowl layers was higher than that of Lushi Green-shelled layers. During the laying period from 21 to 51 weeks, egg yolk cholesterol content decreased in the period of 21 to 31 weeks and tended to increase in the period of 31 to 51 weeks.

\section{ACKNOWLEDGMENTS}

Research supported by Foundation for Development Program of Innovation Team 
from the Ministry of Education of China (\#IRT1236), Earmarked Fund for Modern Agro-Industry Technology Research System (\#CARS-41-k04), Program for the talents and innovative research team from Ministry of Agriculture of China and the Outstanding Youth Foundation of Henan Province (\#104100510013).

\section{REFERENCES}

Baumgartner J, Konceková Z, Benková J, Peškovicová D, et al. (2008). Changes in egg quality traits associated with longterm selection for lower yolk cholesterol content in Japanese quail. Czech. J. Anim. Sci. 53: 119-127.

Bragagnolo N and Rodriguez-Amaya D (2003). Comparison of the cholesterol content of Brazilian chicken and quail eggs. J. Food Compos. Anal. 16: 147-153.

Campo JL (1995). Comparative yolk cholesterol content in four Spanish breeds of hens, an F2 cross, and a White Leghorn population. Poult. Sci. 74: 1061-1066.

de Goede J, Geleijnse JM, Boer JM, Kromhout D, et al. (2012). Linoleic acid intake, plasma cholesterol and 10-year incidence of CHD in 20,000 middle-aged men and women in the Netherlands. Br. J. Nutr. 107: 1070-1076.

Elkin R (2006). Reducing shell egg cholesterol content. I. Overview, genetic approaches, and nutritional strategies. Worlds Poult. Sci. J. 62: 665-687.

Grundy SM (1986). Comparison of monounsaturated fatty acids and carbohydrates for lowering plasma cholesterol. $N$. Engl. J. Med. 314: 745-748.

Hall LM and Mckay JC (1993). The relationship between yolk cholesterol and total lipid concentration throughout the first year of egg production in the domestic fowl. Br. Poult. Sci. 34: 487-495.

Hargis PS (1988). Modifying egg yolk cholesterol in the domestic fowl-a review. World's Poult. Sci. J. 44: 17-29.

Jiang Z and Sim JS (1991). Research note: Egg cholesterol values in relation to the age of laying hens and to egg and yolk weights. Poult. Sci. 70: 1838-1841.

Khera AV, Cuchel M, de la Llera-Moya M, Rodrigues A, et al. (2011). Cholesterol efflux capacity, high-density lipoprotein function, and atherosclerosis. N. Engl. J. Med. 364: 127-135.

Liu X, Zhao HL, Thiessen S, House JD, et al. (2010). Effect of plant sterol-enriched diets on plasma and egg yolk cholesterol concentrations and cholesterol metabolism in laying hens. Poult. Sci. 89: 270-275.

Mahmoud KZ, Gharaibeh SM, Zakaria HA and Qatramiz AM (2010). Garlic (Allium sativum) supplementation: influence on egg production, quality, and yolk cholesterol level in layer hens. Asian-Australas. J. Anim. Sci. 23: 1503-1509.

McNaughton JL (1978). Effect of dietary fiber on egg yolk, liver, and plasma cholesterol concentrations of the laying hen. J. Nutr. 108: 1842-1848.

Menge H, Littlefield LH, Frobish LT and Weinland BT (1974). Effect of cellulose and cholesterol on blood and yolk lipids and reproductive efficiency of the hen. J. Nutr. 104: 1554-1566.

Myant NB (1990). Current approaches to the genetics of coronary heart disease (CHD) including an account of work done at Hammersmith Hospital. Boll. Soc. Ital. Biol. Sper. 66: 1015-1041.

Palafox A (1968). Effect of age, energy source and concentration on yolk lipids and cholesterol. Poult. Sci. 47: 705.

Shafey T, Dingle J and McDonald MW (1998). The relationships between egg yolk cholesterol, egg production and age of the hen in three Australian layer strains. J. King Saud Univ. Agric. Sci. 10: 33-41.

Simcic M, Stibilj V and Holcman A (2009). The cholesterol content of eggs produced by the Slovenian autochthonous Styrian hen. Food Chem. 114: 1-4.

Spencer JV, Becker WA, Mirosh LW and Verstrate JA (1978). Effect of fertilization and age of hen on the cholesterol content of chicken egg yolk. Poult. Sci. 57: 261-264.

Suk YO and Park C (2001). Effect of breed and age of hens on the yolk to albumen ratio in two different genetic stocks. Poult. Sci. 80: 855-858.

Vargas RE and Naber EC (1984). Relationship between dietary fiber and nutrient density and its effect on energy balance, egg yolk cholesterol and hen performance. J. Nutr. 114: 645-652. 